\title{
Study of diesel micro-pilot ignition for gasoline compression combustion on a light duty engine
}

\author{
Guotao Suo and Lin Lv \\ Key Laboratory of High Performance Ship of Ministry of Education, Wuhan University of Technology, Wuhan, China
}

\begin{abstract}
The potential of controlling the gasoline premixed compression ignition combustion using the diesel micro-pilot strategy was investigated to achieve high thermal efficiency and low emissions on a light duty engine. It was found that the gasoline fraction and the second diesel micro-pilot injection timing effectively controlled the combustion phases. Then an experimental study on the engine confirmed that, at 8 bar NMEP, the proposed combustion recipe achieved up to 53\% gross indicated thermal efficiency while the $\mathrm{NO}_{\mathrm{X}}$ and Soot emissions were $1 \mathrm{~g} / \mathrm{kg}$-fuel and $0.1 \mathrm{FSN}$, respectively. Optimization on the proposed combustion strategy showed the potential to meet Euro VI NOx and PM emission limits while achieving higher than $50 \%$ gross indicated thermal efficiency at the above operating point.
\end{abstract}

Keywords: gasoline compression ignition; diesel Micro-Pilot; low temperature combustion; high efficiency; clean combustion.

\section{Introduction}

Rising fuel costs have driven a need of high efficient combustion for the internal combustion engine. This has placed the diesel engine in the spotlight due to its higher efficiency compared to the gasoline engine. However, current and future emission legislations place stringent thresholds on diesel engine emissions. All these demands require the advanced combustion technology which can simultaneously achieve high efficiency and low emissions for diesel engines.

Up to date, many strategies have been investigated to meet the future requirements of clean and high efficient combustion on diesel engines. Most of the current strategies fall into the category of Low Temperature Combustion (LTC). The LTC mode is beneficial to reduce $\mathrm{NO}_{\mathrm{X}}$ due to high activation energy of NO formation reactions [1]. In addition, utilizing a long ignition delay allows adequate time for mixing of fuels and intake air prior to the start of combustion, so rich fuel regions are reduced and soot formation is inhibited. Many researchers have shown HCCI and PCCI to be promising solutions to both $\mathrm{NO}_{\mathrm{X}}$ and soot reduction [2-7]. However, the well-mixed fuels led to the high cylinder pressure rise rate and this restricted the maximum load at which HCCI can operate [8-9].

Many solutions were proposed to control the combustion processes and keep the cylinder pressure rise rate below a certain threshold. Nissan et al. [10-11] exploited the MK concept that injecting diesel fuel early with higher swirl and colder EGR to achieve the combustion when the injection is over. Toyota et al. [12] used a fuel pilot injection strategy to create a homogeneous mixture and the combustion is triggered after the main injection. In addition, different injection and EGR strategies

\footnotetext{
a Corresponding author : lulinwhut@163.com
} 
were studied in order to keep low emissions and fuel consumption [13-16] on diesel engines. Unfortunately, the solutions mentioned above cannot be used in the whole operating range of the engine since at high load the pilot injection might auto ignite before the main injection being carried out.

Because the LTC mode mainly relies on the spontaneous auto ignition, all the variables that surround the combustion process would affect the phase of combustion. In view of the existing fuel infrastructure, most of the researches have been conducted using either strictly gasoline or diesel fuel. Although gasoline has a high volatility which makes a well-premixed charge, the poor auto ignition quality brings difficulty to achieve combustion at low-load conditions [17-18]. Conversely, the superior auto ignition quality of diesel fuel can result in difficulty controlling the combustion phase as engine load is increased. In recent years, many researchers suggested that the best fuel for HCCI operation may have auto ignition quality between that of diesel fuel and gasoline. Based on the work of Bessonette et al. [19] and Inagaki et al. [20], it is likely that different fuels ratios will be required at different operating conditions (e.g., a high cetane fuel at light load and a low cetane fuel at high load). Sage L. Kokjohn et al. [21-22] spent lots of effort on the dual-fuel HCCI and PCCI combustion study using in-cylinder fuel blending on a heavy duty engine which proved that the introduction of the second fuel with different reactivity can help control the combustion phase.

In this paper, the diesel micro-pilot based gasoline compression ignition strategy is explored in order to demonstrate the possibility of simultaneously achieving high thermal efficiency and extremely low emissions on a light duty single cylinder engine. The critical parameters such as gasoline to diesel mass ratio, EGR fraction, diesel micro-pilot injection timing are investigated both analytically and experimentally at a given operating point. With the testing results, the significance of the combustion strategy is illustrated.

\section{Experimental}

In this paper, the single cylinder engine experiment was conducted. The EGR rate, gasoline fraction and diesel pilot 2 injection timing were investigated on the single cylinder engine.

Table 1 shows the engine test conditions. The fuels used were \#2 diesel fuel and RON87 gasoline. The low heat value of the diesel fuel is $42.5 \mathrm{MJ} / \mathrm{kg}$ while that of the gasoline is $43.2 \mathrm{MJ} / \mathrm{kg}$.

Table 1. Test Conditions.

\begin{tabular}{|c|c|}
\hline Criteria & Details \\
\hline Number of Diesel Pulses & 2 (1st for squish conditioning and 2nd for combustion control) \\
\hline Diesel Rail Pressure & 600 bar \\
\hline Gasoline Port Fuel Injection Timing & End of Injection at $322^{\circ}$ ATDC \\
\hline Diesel Pilot Timing for EGR Sweep & Pilot $1=-55^{\circ}$ ATDC, Pilot $2=-15^{\circ}$ ATDC \\
\hline Intake Manifold Temperature & $45^{\circ} \mathrm{C}$ \\
\hline Engine Operating Conditions & 1900 RPM, 8 bar NMEP \\
\hline
\end{tabular}

\section{Results and discussion}

\subsection{EGR sweep results}

The EGR sweep was firstly conducted at 1900 RPM and 8 bar NMEP in order to identify the proper EGR fraction to further evaluate the impacts of PFI sweep and diesel injection timing on the combustion process, engine performance and emissions. The EGR sweep was conducted at $90 \%$ and 80\% PFI respectively with first diesel direct injection timing fixed at $-55^{\circ}$ ATDC.

As EGR fraction increased, the second diesel injection timing was advanced to maintain the CA50 at $4^{\circ}$ ATDC around to achieve high thermal efficient, as shown in Figure 1 and Figure 2. The diesel fuel quantity was split equally between the two pilot pulse events. Figure $\mathbf{3}$ compares the combustion 
durations of different PFI. The combustion durations were extended with increase in EGR fraction mainly due to the charge dilution [23]. It can be seen in Figure 4 that $\mathrm{NO}_{\mathrm{X}}$ reduced with increase in EGR fraction. For the $\mathrm{NO}_{\mathrm{X}}$ to be below the Euro VI levels, the fuel specific $\mathrm{NO}_{\mathrm{X}}$ must be below 2 $\mathrm{g} / \mathrm{kg}$ of fuel which means the minimum EGR fraction should be $40 \%$.

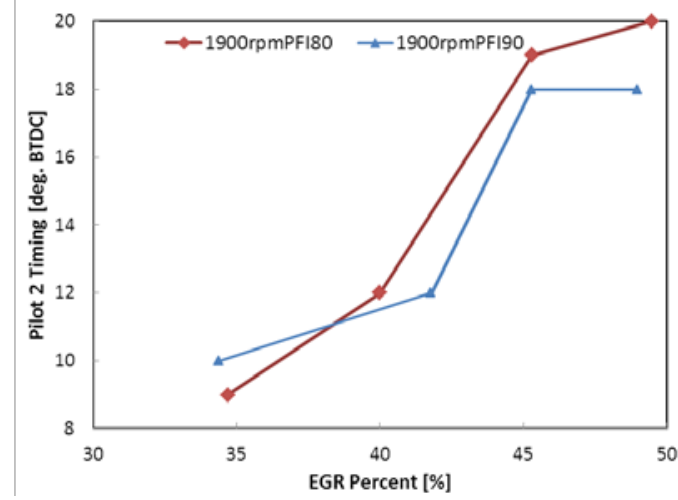

Figure 1. EGR Sweep - Pilot 2 Timing.

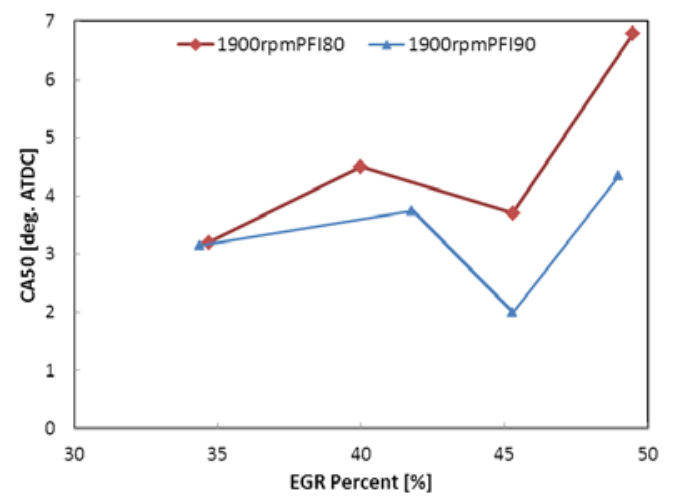

Figure 2. EGR Sweep - CA50.

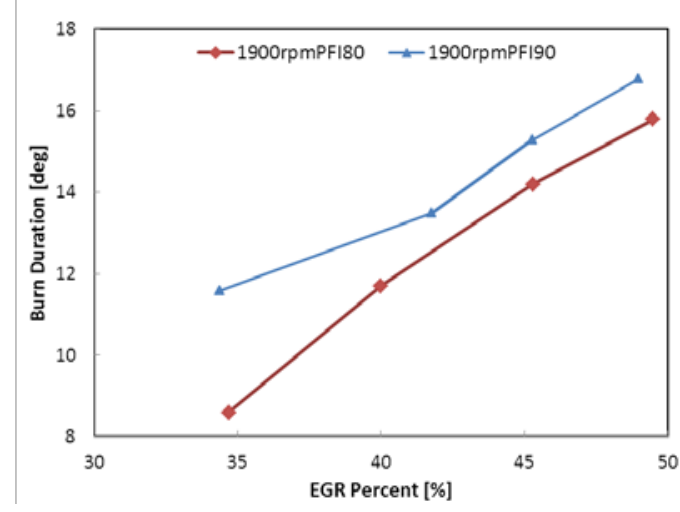

Figure 3. EGR Sweep - Burn Duration.

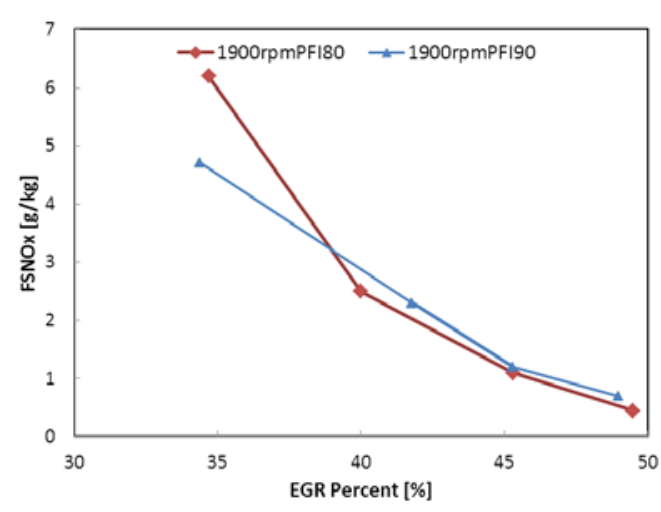

Figure 4. EGR Sweep - Engine Out $\mathrm{NO}_{\mathrm{X}}$.

Figure 5 shows the unburnt HC emissions with EGR sweep, and the more EGR fraction give rise to more unburned $\mathrm{HC}$ emissions. The reduction in heat rejection and flame propagation with increase in EGR fraction played a bigger role in this EGR fraction range. Figure 6 shows the FSN results. The FSN decreased with increase in EGR fraction, which is not typical behavior of diesel combustion. The hypothesis here is that the peak flame temperature of diesel micro-pilot combustion was outside of the $\mathrm{NO}_{\mathrm{X}}$ and Soot production zone. For the PM to be below Euro VI limit, the FSN should be less than 0.2 which means the EGR fraction should be higher than $40 \%$. Based on the above results, the EGR $40 \%$ was selected for the next step study in order to quantify the impact of diesel fuel injection strategy on the combustion process, engine performance and emissions.

\subsection{PFI gasoline fraction sweep}

PFI gasoline fraction sweep was conducted at 1900 RPM, 8 bar NMEP and 40\% EGR fraction. Figure 7 shows the cylinder pressure trace for three different PFI fractions. As it can be seen, with increasing in PFI fraction, the rate of cylinder pressure rise reduced, and therefore leading to slower combustion. 


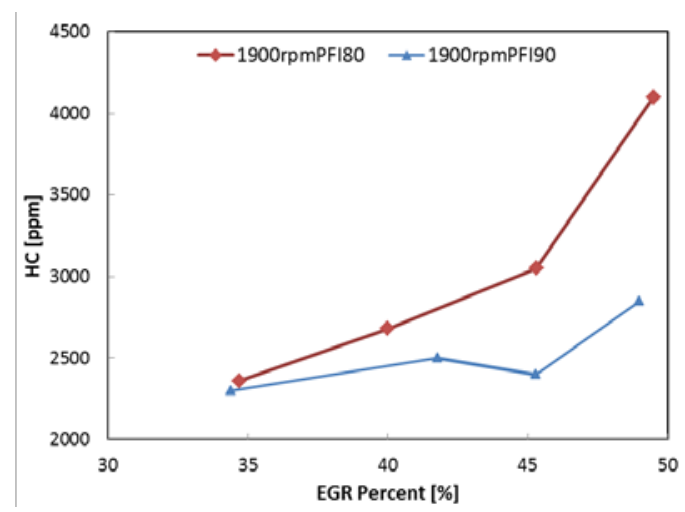

Figure 5. EGR Sweep - UHC Emissions.

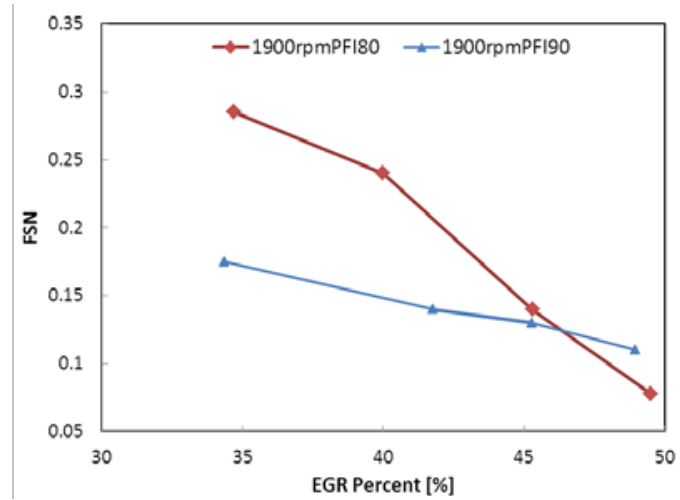

Figure 6. EGR Sweep - FSN.

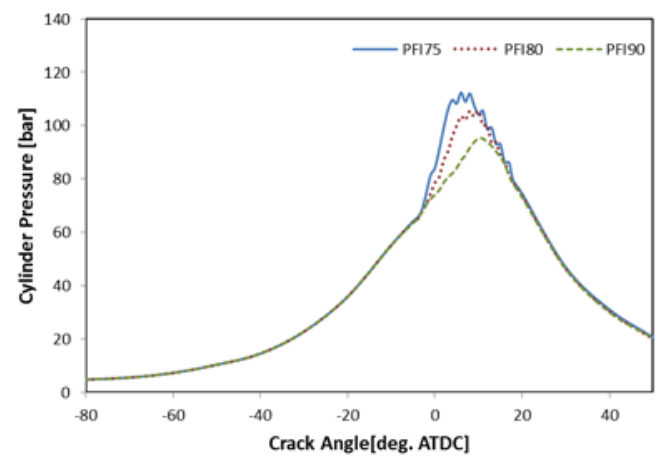

Figure 7. PFI Fraction Sweep - Cylinder Pressure.

Figure 8 below shows the combustion duration is extended and the CA50 gets retarded while increasing the PFI fraction. These results prove that by keeping the gasoline fraction in a reasonable range, it is capable to control the combustion phase.

The gross indicated efficiency results look pretty close to each other with PFI fraction sweep. With the timing chosen on this test, the $80 \%$ PFI gasoline fraction had the best gross indicated efficiency as shown in Figure 9. The $\mathrm{NO}_{\mathrm{X}}$ decreased with increase in PFI mainly due to the slower rate of combustion process and lower peak combustion temperature.

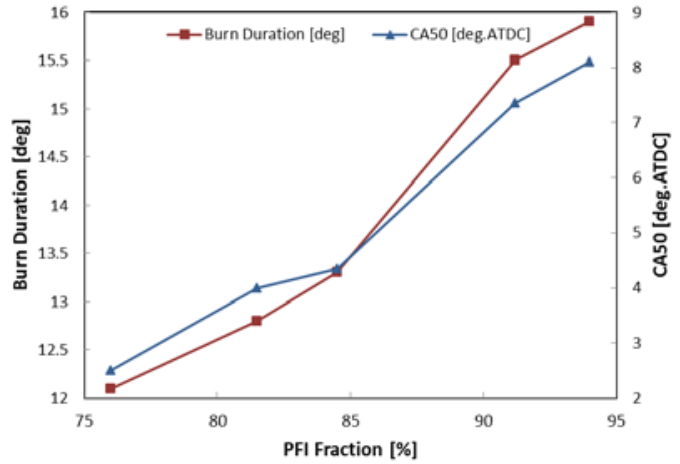

Figure 8. PFI Fraction Sweep - Burn Duration\&CA50.

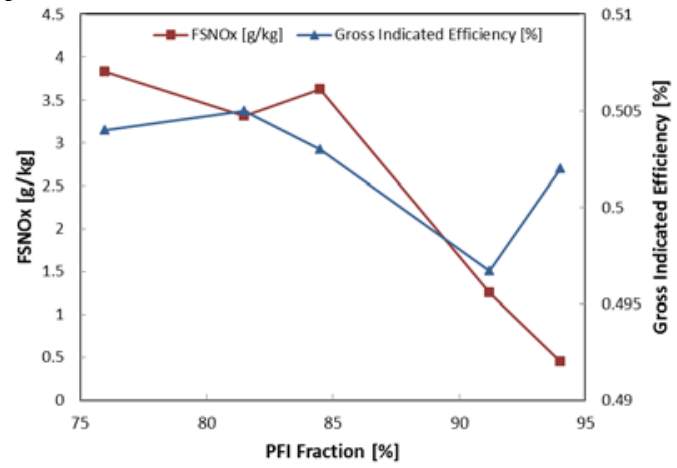

Figure 9. PFI Fraction Sweep - FSNOX\&GIE.

\subsection{Diesel pilot 2 injection timing sweep}

Diesel pilot 2 injection timing sweep was conducted at 1900 RPM, 8 bar NMEP, 40\% EGR fraction, and $90 \%$ PFI fraction. The Pilot 1 timing was kept constant at $-45^{\circ}$ ATDC. The Pilot 2 was varied 
from -10 to $-25^{\circ}$ ATDC. The total fueling and the EGR fraction were held constant. The first NMEP set point was achieved using the Pilot 2 timing of $-15^{\circ}$ ATDC. As a result of Pilot 2 timing change, the NMEP changed from the original 8 bar at the said condition above. The NMEP plot is shown in Figure 10.

For a fixed fueling, the NMEP increased with advance in Pilot 2 timing as expected. However, the trend reversed when the timing was advanced beyond $-20^{\circ}$ ATDC. This is because the ignition event was controlled by chemical kinetics and not by the DI mixing. Figure 11 shows the CA50 versus Pilot 2 timing. With advance in Pilot 2 timing until $-20^{\circ}$ ATDC the CA50 moved close to TDC, then the trend reversed because of the reason noted above.

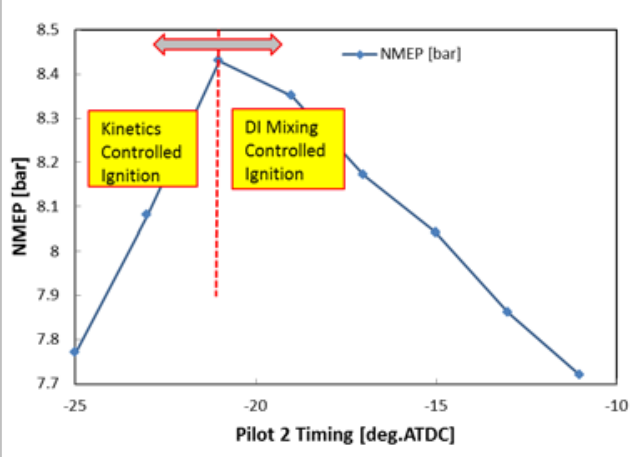

Figure 10. Diesel Pilot 2 Timing Sweep - NMEP.

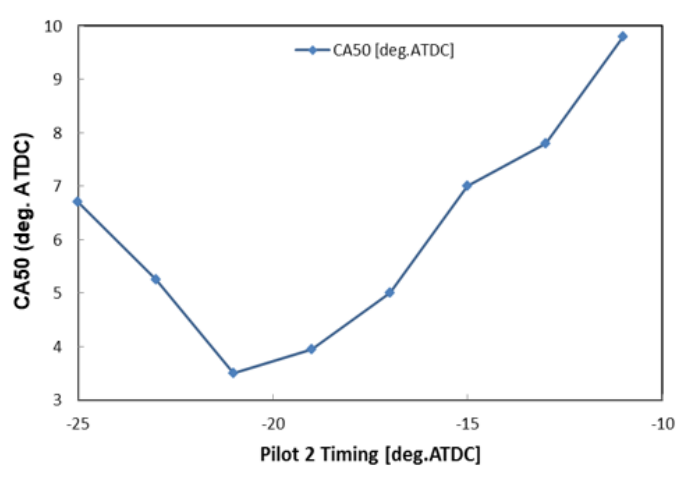

Figure 11. Diesel Pilot 2 Timing Sweep - CA50.

Figure 12 shows the fuel specific $\mathrm{NO}_{\mathrm{X}}$ and gross indicated efficiency. As expected, the peak gross indicated efficiency was achieved with pilot 2 diesel injection timing at $22 \mathrm{deg}$. CA before TDC. The best gross efficiency measured was $53 \%$. What's more, the $\mathrm{NO}_{\mathrm{X}}$ at the point was roughly same level as the Euro VI $\mathrm{NO}_{\mathrm{X}}$ levels.

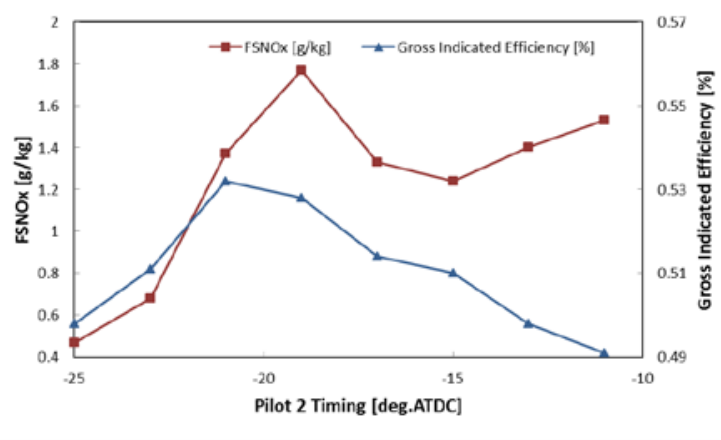

Figure 12. Diesel Pilot 2 Timing Sweep - $\mathrm{FSNO}_{\mathrm{X}}$ \& Gross Indicated Efficiency.

\section{Conclusions}

This study explored using in-cylinder blending of two fuels with different activities to control the combustion phase and heat release rate. In-cylinder fuel blending uses port fuel injection of gasoline and early cycle, direct injection of diesel fuel with two pilot injections. Single cylinder engine experimental testing was performed using at engine load of 8 bar NMEP and engine speed of 1900 RPM.

It was observed that the gasoline percentage can be effectively used to control the combustion phase and heat release rate. With the increase in gasoline percentage, the combustion phase will get retarded. The first diesel pilot injection timing does not impact the combustion process as much as the 
second diesel pilot injection timing. Regarding to the second pilot injection timing, there is an optimal timing to achieve the best thermal efficiency and low emissions.

During this primary study, the experimental testing measured high up to 53\% indicated thermal efficiency while the $\mathrm{NO}_{\mathrm{X}}$ emission is below Euro VI level.

\section{Acknowledgements}

The authors would appreciate the support from Cummins on offering the testing facility and single cylinder engine for the experimental study. The experimental testing was supported by Rajkumar Subramanian from Cummins Advanced System Integration team. Sam Gerkler who is engineering director from Cummins also gave lots of guidance during the overall experimental testing.

\section{Nomenclature}

$\begin{array}{ll}\text { ATDC } & \begin{array}{l}\text { after top dead center, deg } \\ \text { the crank angle when the engine released } 50 \% \text { of the total combustion heat, } \\ \text { deg.ATDC }\end{array} \\ \text { EG5 } & \begin{array}{l}\text { exhaust gas recirculation } \\ \text { FSN }\end{array} \\ \text { filter smoke number } \\ \text { hCCI } & \text { lowogeneous charge compression ignition } \\ \text { LTC } & \text { net indicated mean effective pressure, bar } \\ \text { NMEP } & \text { premixed charge compression ignition } \\ \text { PCCI } & \text { port fuel injection fraction, \% }\end{array}$

\section{References}

1. Turns, S. R. WCB/McGraw-Hill, Boston, (2000)

2. Bression, G., Soleri, D., Savy, S. et al. SAE Int. J. Fuels Lubr, 1(1):37-49 (2008)

3. Hardy, W.L. and Reitz, R.D. SAE Technical Paper, 01-0026 (2006)

4. Opat, R., Ra, Y., Gonzalez, et al. SAE Technical Paper, 01-0193 (2007)

5. Yokota, H., Kudo, Y., Nakajima, et al. SAE Technical Paper, 970891 (1997)

6. Manente, V., Tunestal, P., Johansson, B., and Cannella, W. SAE Technical Paper, 01-0871 (2010)

7. Dec, J.E., Yang, Y., and Dronniou, N. SAE Int. J. Engines, 4(1): 1169-1189 (2011)

8. Sjoberg, M., Decl, J.E. and Gernansky, N.P. SAE Technical Paper, 01-0113 (2005)

9. Sjoberg, M., Decl, J.E. SAE Technical Paper, 01-0629 (2006)

10. Ogawa, H. Kimura, S., Koike, M., et al. SAE Technical Paper, 01-2792 (2000)

11. Kawamoto, K.,Araki, T., Shinzawa, M., et al. SAE Technical Paper, 01-1868 (2004)

12. Hasegawa, R., Yanagihara, H. SAE Technical Paper, 01-0745 (2003)

13. Kimura, S., Ogawa, H., Matsui, Y., et al. Int. J. Engine res., vol 3, no.4, pp 249-259 (2002)

14. Su, W., Lin, T., Pei, Y. SAE Technical Paper, 01-741 (2003)

15. Mueller, C.J., Martin, G.C., Briggs, T.E., Duffy, K.P. SAE Technical Paper, 01-1843 (2004)

16. Dronniou, N. Lejeune, M., Balloul, I., et al. SAE Technical Paper, 01-3726 (2005)

17. Liu H., Yao M., Zhang B. and Zheng Z. Energy \& Fuels, vol.22, no.4, pp2207-2215 (2008)

18. Christensen, M., Hultqvist, A., and Johansson, B. SAE Technical Paper, 01-3679 (1999)

19. Bessonette, P.W., Schleyer, C.H., Duffy, K.P., et al. SAE Technical Paper, 01-0191 (2007)

20. Inagaki, K., Fuyuto, T., Nishikawa, et al. SAE Technical Paper, 01-0028 (2006)

21. Sage, L. Kokjohn., Reed, M. Hanson., Derek, A. Splitter, SAE Technical Paper, 01-2647 (2009)

22. Reed, M. Hanson., Sage, L. Kokjohn,, Derek, A. Splitter, SAE Technical Paper, 01-0864 (2010)

23. Hawley, J.G., C.J. Brace and F.J. Wallace, Academic Press, Boston, 280-357 (1998) 